\title{
Untying the Gordian knot: policies, practices, and ethical issues related to banking of umbilical cord blood
}

\author{
Joanne Kurtzberg, ${ }^{1}$ Anne Drapkin Lyerly, ${ }^{2}$ and Jeremy Sugarman ${ }^{3}$
}

${ }_{1}^{1}$ Pediatric Blood and Marrow Transplant Program, Department of Obstetrics and Gynecology, Duke University Medical Center, Durham, North Carolina, USA. ${ }^{2}$ Center for the Study of Medical Ethics and Humanities and Department of Obstetrics and Gynecology, Duke University Medical Center, Durham, North Carolina, USA. ${ }^{3}$ Phoebe R. Berman Bioethics Institute and Department of Medicine, Johns Hopkins University, Baltimore, Maryland, USA.

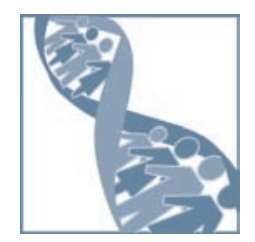

Since the first successful transplantation of umbilical cord blood in 1988, cord blood has become an important source of hematopoietic stem and progenitor cells for the treatment of blood and genetic disorders. Significant progress has been accompanied by challenges for scientists, ethicists, and health policy makers. With the recent recognition of the need for a national system for the collection, banking, distribution, and use of cord blood and the increasing focus on cord blood as an alternative to embryos as a source of tissue for regenerative medicine, cord blood has garnered significant attention. We review the development of cord blood banking and transplantation and then discuss the scientific and ethical issues influencing both established and investigational practices surrounding cord blood collection, banking, and use.

In 1988, a 6-year-old boy from North Carolina with Fanconi anemia was transplanted in Paris with HLA-matched umbilical cord blood from his baby sister (1). Most scientists and physicians at the time were highly skeptical, doubting that a few ounces of cord blood contained sufficient stem and progenitor cells to rescue bone marrow after myeloablative therapy. However, this child engrafted without incident, fully reconstituting his blood, bone marrow, and immune system with donor cells. He remains well and durably engrafted with donor cells 17 years following the original transplant (J. Kurtzberg, personal communication).

\section{From experimentation to practice: development of cord blood transplantation}

Over the 5-6 years following the first cord blood transplant, approximately 60 additional transplants between HLA-matched siblings were performed worldwide. Reports of results to a volunteer registry (2) demonstrated that cord blood contained sufficient numbers of stem and progenitor cells to reconstitute the entire hematopoietic system of a child after myeloablative therapy and that the incidence of graft-versus-host disease (GVHD) was 10fold lower than that seen after transplantation with HLA-matched bone marrow obtained from a sibling.

At this time it was becoming apparent that the diversity of HLA alleles and antigens was vast and that it was never going to be possible to find fully matched related and unrelated adult donors for all patients in need of allogeneic transplantation therapy from then-available sources. The National Marrow Donor Foundation (NMDP) and other international registries successfully recruited, typed, and listed millions of volunteer unrelated adult donors, but only $25-50 \%$ of patients in need could locate sufficiently matched

Nonstandard abbreviations used: GVHD, graft-versus-host disease; HRSA, Health Resources and Services Administration; IOM, Institute of Medicine.

Conflict of interest: The authors have declared that no conflict of interest exists.

Citation for this article: J. Clin. Invest. 115:2592-2597 (2005).

doi:10.1172/JCI26690. donors in a timely fashion. Donors for patients of minority ethnic backgrounds were even scarcer and more difficult to locate. To provide donors for all patients in need, transplant physicians needed to find a way to transplant partially mismatched grafts. Transplants using partially HLA-mismatched adult hematopoietic stem cells from mobilized blood or bone marrow, with or without $\mathrm{T}$ cell depletion, were failing because of high rates of graft failure, severe GVHD, and failure of the immune system to properly reconstitute for several years after transplantation, leading to death from opportunistic infections (3-5).

The observation that transplantation of HLA-matched umbilical cord blood from donors that were related family members caused less GVHD led to the hypothesis that this graft source might be transplantable in the unrelated-donor setting. To this end, in 1991, the first public cord blood bank in the world was created at the New York Blood Center (6). Cord blood, the residual blood from the baby remaining in the placenta or "afterbirth" delivered in the third stage of labor, was collected ex utero, tested for bloodborne pathogens, cryopreserved, and stored under liquid nitrogen until selected for a transplant patient in need.

In 1993, the first unrelated-donor umbilical cord blood transplant in the world, using a cord blood unit from the bank at the New York Blood Center, was performed in a 3-year-old child with recurrent $T$ cell acute lymphoblastic leukemia. In 1996, the outcomes of this transplant and the next consecutive 24 unrelateddonor cord blood transplants performed at Duke University Medical Center using cord blood units banked at the New York Blood Center were reported (7). Important observations in these patients and subsequent reports from other centers and registries including the New York Blood Center and the European Cord Blood Registry, Eurocord (8-13) demonstrated that unrelateddonor cord blood could engraft in the bone marrow of children undergoing myeloablative therapy for leukemias and genetic diseases (14-18), that reasonable outcomes could be achieved using partially HLA-mismatched grafts, that the incidence and severity of acute and chronic GVHD were lower and milder than those seen 


\begin{tabular}{lcc} 
Table 1 \\
Reported engraftment and survival rates following unrelated- \\
donor cord blood transplant \\
\hline \\
Condition & Engraftment (\%) & Survival (\%) \\
Infants with leukemia & 80 & 55 \\
Children with leukemia & 75 & 49 \\
Adults with leukemia & $28-78$ & 75 \\
Patients with nonmalignant diseases & $70-80$ & 80 \\
\hline
\end{tabular}

in recipients of bone marrow transplants from unrelated donors $(8,11)$, but that graft-versus-leukemia effects were retained (13). It also became apparent that cell dose strongly correlated with clinical outcomes, including time to engraftment and probability of overall engraftment and survival $(7,10)$. Engraftment times were observed to be slower than those of bone marrow or mobilized peripheral blood $(8,12)$.

Over the 12 years since the first unrelated-donor cord blood transplant was performed at Duke University Medical Center, there have been more than 6,000 unrelated-donor transplants performed in more than 150 locations around the world. In the vast majority of these transplants, HLA mismatching between donor and recipient was present at 1 or 2 HLA antigens. Efficacy has been demonstrated in both children and adults with leukemias (7-13, 19-23) and children with hemoglobinopathies $(14,15)$, immunodeficiency syndromes (16), bone marrow failure syndromes (24), and inborn errors of metabolism $(17,18)$. Reported survival rates (Table 1) are similar to those seen in patients transplanted with matched bone marrow from unrelated donors despite the fact that the cord blood was generally mismatched at 1 or 2 HLA loci. The strong correlation of cell dose with engraftment and survival following cord blood transplant has been confirmed. Several retrospective registry analyses of more than 3,000 patients published over the past few years have shown that cord blood engrafts more slowly than bone marrow and that the cumulative incidence of engraftment is slightly lower than that of bone marrow; that the incidence and severity of acute GVHD is lower after cord blood transplantation as compared with bone marrow transplantation (11); and that overall survival rates are comparable. In one study, results obtained following transplant of cord blood from a 5/6 mismatched unrelated donor were found to be equivalent to those obtained following transplant of bone marrow from a 6/6 matched unrelated donor (12). No prospective trials comparing transplant outcomes after bone marrow or cord blood transplantation have been conducted to date.

How much is enough? Initially, because of early results correlating cell dose with engraftment and survival, cord blood transplantation was restricted to use in children and small adults, generally weighing less than $40 \mathrm{~kg}$. More recently, however, the use of cord blood has been extended to include adults, allowing for better definition of cell dose limitations and thresholds (19-24). The results of these transplants have helped define a requirement for a minimum cell dose of $3 \times 10^{7}$ to $3.5 \times 10^{7}$ nucleated cells $/ \mathrm{kg}$ in order to obtain acceptable clinical outcomes (25). Since only $12 \%$ of the current inventory in established public cord blood banks contains sufficient cells to deliver this dose to patients weighing more than $60 \mathrm{~kg}$, alternative strategies to increase cell dose for adults and larger pediatric patients have been explored. Ex vivo expansion from bulk cord blood or $\mathrm{CD} 34^{+}$cord blood cells selected using various cytokines or supporting cells promotes 10- to 200-fold increases in nucleated cells, clonal progenitor cells, and CD $34^{+}$cells in vitro. However, augmentation of conventional, unmanipulated cord blood for transplantation has not yielded significant improvements in the observed time to engraftment or overall probability of engraftment $(26,27)$, and it remains unclear why. No current testing procedures are capable of adequately measuring the stem cell population, and in vitro and animal studies currently use surrogates for such assays, which may not correlate well with clinical outcomes - a clear technological deficiency in the field. Alternatively, we may simply be unable to expand true cord blood stem cells with these procedures.

Pilot trials combining 2 cord blood units for a single patient look promising (28). The use of reduced-intensity preparative regimens in adult patients who have had prior cycles of standard chemotherapy to treat a malignant condition with engraftment of lower-dosed single umbilical cord blood grafts has also been reported $(29,30)$. However, this approach has not been successful in children because of graft rejection in these younger, immunocompetent hosts. Recently, CD34+-selected, haploidentical cells from mobilized peripheral blood of adult donors have been used to augment cord blood transplantation in adults, leading to early neutrophil recovery and the cord blood graft providing durable marrow and immune reconstitution (31).

The only prospective multicenter trial of unrelated-donor cord blood transplantation to date - the Cord Blood Transplantation Study - was sponsored by the National Heart, Lung, and Blood Institute and performed from 1997 to 2004. The study funded the establishment of 3 unrelated cord blood banks that followed common quality standards and operating procedures with respect to donor recruiting; screening (donors are screened for events in their medical history that would exclude them as donors, e.g., multiple pregnancy, prematurity, placental deformity, self or sibling diagnosed with cancer, prior receipt of a transplant, or demonstrating risk behaviors likely to increase the chance of infection with blood-borne infectious diseases); collection of informed donor consent; obtaining medical histories; obtaining blood samples from maternal donors; and cord blood collection, processing, testing, cryopreservation, and storage, as well as searching for and releasing cord blood units for transplantation (32). Twenty-six transplant centers participated in a prospective clinical trial designed to examine the safety and efficacy of unrelated cord blood transplantation in infants, children, and adults with malignancies; children with congenital immunodeficiency disorders; and children with inborn errors of metabolism. The study participants employed common preparative regimens, prophylaxis against GVHD, and supportive care measures (32-35). Results in children with malignant and nonmalignant conditions were favorable, with $55 \%$ survival in children with malignancies and $78 \%$ survival in children with nonmalignant conditions. Results in a very high-risk group of adults were inferior to those seen in children and in individuals receiving bone marrow from an unrelated donor. Subsequent studies in adults, reported by single centers or registries, revealed more encouraging results $(19-23,28)$. The cumulative incidence of engraftment by day 42 after transplantation was approximately $80 \%$ in all study strata including adults and children as well as children with malignant diseases, inborn errors of metabolism, and immunodeficiency syndromes. Factors adversely affecting engraftment or survival 
included lower cell doses, pretransplant CMV seropositivity in the recipient, non-white descent, and greater HLA mismatching.

The major obstacles to the success of unrelated cord blood transplantation today include slower engraftment times resulting in longer hospitalizations and increased resource utilization (e.g., packed red blood cells and platelet transfusions), lack of sufficient numbers of larger cord blood units containing enough cells for transplantation in an adult, and an increasing need for ethnic diversity among donors to achieve closer HLA matching.

\section{Cord blood collection}

The cord blood, which typically would be discarded at birth with the placenta, can be collected without physical risk to the mother or baby donor. Cord blood can be collected from the delivered placenta (ex utero) (Figure 1) or during the third stage of labor (in utero). Many public cord blood banks employ dedicated staff to perform ex utero collections away from the delivery room so that the privacy of the family is preserved and so clinicians are not distracted from their usual practices. Alternatively, obstetricians or midwives perform in utero collections while waiting for the placenta to deliver. In either case, after sterile preparation, the umbilical vein is punctured with a 17-gauge needle attached to a sterile, closed system collection bag containing citrate phosphate dextrose anticoagulant, which is positioned lower than the placenta. Blood flows from the placenta through the cord into the bag over approximately 9-10 minutes. Experienced collectors harvest an average of $110 \mathrm{ml}$ from a single placenta. The cord blood unit is labeled and subsequently shipped to the bank for processing, testing, cryopreservation, and storage.

The issue of obtaining consent for collection of cord blood has been controversial in the field of cord blood transplantation (36, $37)$. Historically, the cord blood was considered to be the property of the hospital in which the baby was born, to be used, if desired, without patients' express consent. This practice, however, neglected the fact that for some women the placenta would not necessarily be considered a medical waste product, perhaps for some very important cultural reasons (38). Furthermore, once it was discovered that cord blood was rich in hematopoietic stem and progenitor cells that could be used in human transplantation, express consent for the collection of cord blood has been required for public banking. The necessity of consent was further recognized with the appreciation that collection for banking and transplantation required additional medical and personal information about newborns and their mothers. After being given relevant information and the opportunity to have any questions answered, if the cord blood is to be collected and saved, mothers currently must sign a consent form that indicates: (a) the donation of her baby's cord blood is volun-

\section{Figure 1}

Cord blood harvest following delivery. The placenta is suspended, fetal side down, in a stand lined with a clean chuck pad. The cord is brought down and gently tethered onto a work surface below. The cord is prepped with betadine and alcohol. The umbilical vein is punctured with a 17-gauge needle attached to a sterile, pre-barcoded collection bag containing $25 \mathrm{ml}$ citrate phosphate dextrose anticoagulant, which is placed on a rocking scale. The cord blood flows into the bag by gravity over approximately 9 minutes. Cessation of flow is indicated by stabilization of the bag weight on the scale. After completion of the collection, the tubing is stripped and heat sealed. The cord blood collection bag is transported to the processing laboratory. tary; (b) she gives permission for her blood and the cord blood to be tested for blood-borne pathogens, e.g., HIV, hepatitis B and C, syphilis, human $\mathrm{T}$ cell lymphotropic virus, and West Nile Virus, and agrees to provide a detailed family medical history to the bank; (c) the cord blood is not being stored for personal use by the baby or other relatives and instead will be listed on a registry of unrelated donors and made available to patients in need of donors for unrelated-donor transplantation; (d) she may be contacted in the future by the bank to obtain follow-up information on the baby's health; and (e) she understands what measures will be used to protect her confidentiality and that of the baby. Unlike adult donor registries, the identity of a cord blood donor is not revealed to the recipient, and the recipient may not contact the donor in the future.

The timing of the provision of maternal consent also remains controversial. The vast majority of banks believe that consent should be obtained from the mother before collection of the cord blood. A minority of banks collect the cord blood without the mother's knowledge or consent and only subsequently ask the mother for permission to keep the cord blood if the collection was successful (36). The majority of practitioners and blood bank personnel also agree that consent should not be obtained from a woman in active labor or in other circumstances where her decision-making capacity is compromised due to narcotic or other mind-altering analgesics. However, consent from a woman in early

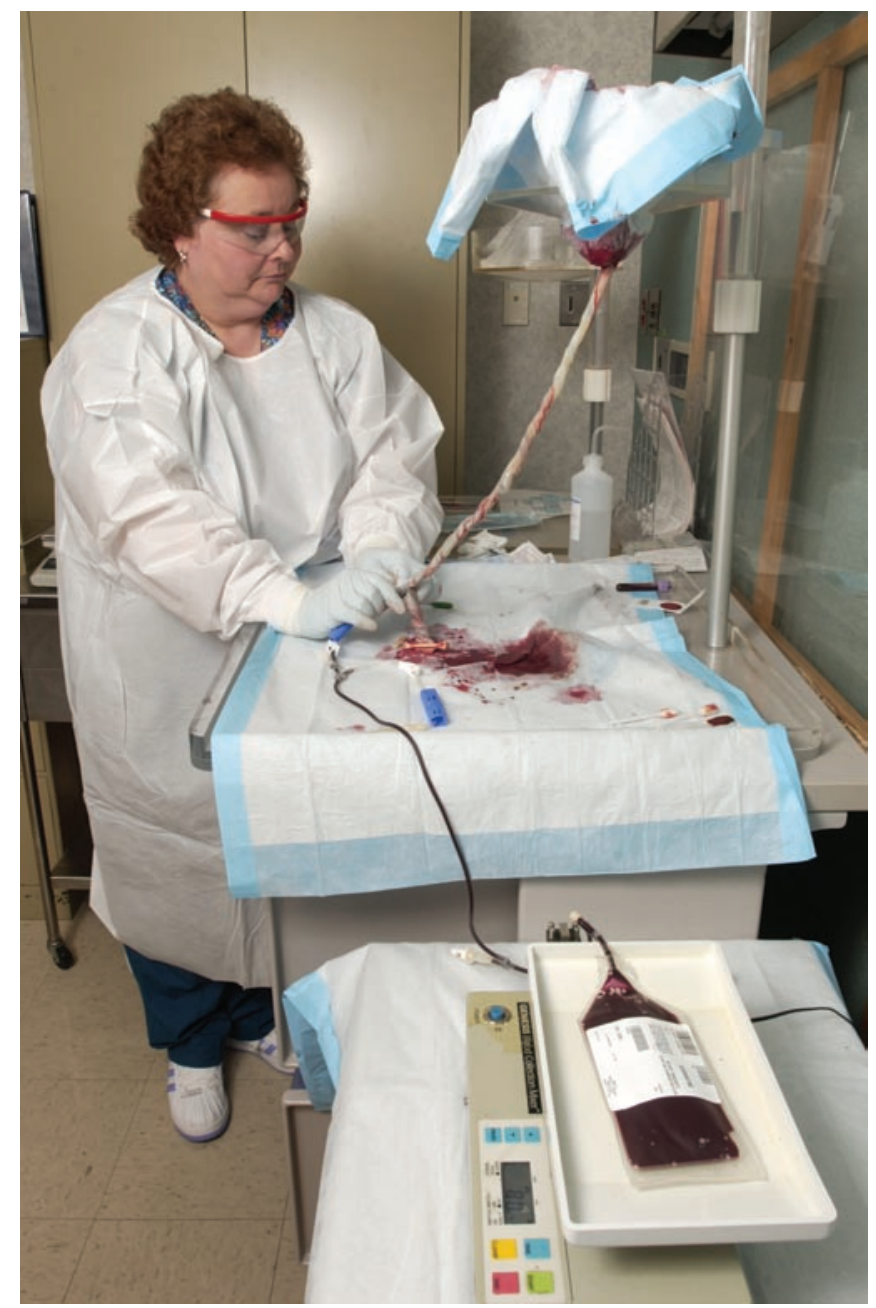


labor has been allowed and advocated by some (37). Despite efforts to recruit women during the third trimester of pregnancy and obtain their informed consent well before the onset of labor, many pregnant women in labor come to the hospital interested in cord blood donation but without having given prior consent. Some centers have addressed this situation by having pregnant women in early labor sign a short or "mini" consent form allowing collection of the cord blood and maternal samples and then meet with her after she recovers from the delivery to educate her and obtain full informed consent for subsequent cord blood banking.

Although there is a general consensus that informed consent for the collection, storage, and use of cord blood should be obtained prior to labor and delivery, variations on the practice have raised further questions about justice and the allocation of resources. As has been previously noted, justice requires the establishment of mechanisms to ensure that all participants have a fair opportunity to participate in umbilical cord blood banking and use (39). The few banks that obtain consent after admission to the hospital or following collection of bankable units have in fact had considerable success in banking units from otherwise underrepresented populations (37). The data highlight the fact that policy making regarding informed consent involves a balance of protecting the interests of donor families and the challenges of equitable recruitment. Thus, recruitment and consent should proceed with sensitivity to the wide range of cultural beliefs about the placenta and umbilical cord (38), donor wariness about participating in an activity perceived as investigational, and suspicion that members of the donor's community will not reap the benefits of this technology.

Concerns about the extent of commercialization of cord blood banking have been highlighted by recent patent litigation. A private biotechnology company, PharmaStem Therapeutics Inc., has claimed that its patents covering collection, cryopreservation, storage, and use of cord blood entitle it to licensing fees (40). To this end, the company brought suit against private banks that had not signed their licensing agreement and sent letters to approximately 25,000 obstetricians asking them not to collect cord blood for 5 private cord blood banks that had not obtained a license with PharmaStem Therapeutics Inc., claiming potential liability for patent infringement. Following a US federal court order in July 2004 prohibiting PharmaStem from further contacting obstetricians due to the fact that it had made "false and misleading" statements to obstetricians, a September 2004 ruling found that PharmaStem failed to prove infringement of its patents because the banks did not sell or offer to sell cryopreserved cord blood (41). Most recently, the US patent office reexamined 1 of the 2 PharmaStem patents in question and rejected the company's related claims (42).

\section{Cord blood banking}

Cord blood transplantation has been made possible in large part by the creation of worldwide umbilical cord blood blanks. There are 2 types of cord blood banks, public and private. Unrelated-donor transplant programs employ public banks as their source of donor cord blood units. These cord blood units are donated on a volunteer basis by women delivering healthy babies at term. Private banks, which are for-profit entities, store "directed donations" collected by obstetricians from babies born into families who intend to use the cord blood for the baby from whom it came (autologous donation) or for another family member in need of future transplantation therapy.

As commercial cord blood banking has proliferated, its ethical justification has been widely debated $(39,43-46)$. In addition to the issues such as patent infringement that can accompany commercialization, private banking has raised a number of other concerns.

Generally, an initial storage fee of $\$ 1,000-1,500$ is charged followed by a yearly storage fee of approximately $\$ 100$. While there are a few clear indications for this practice (e.g., a sibling with cancer, a hemoglobinopathy, marrow failure, congenital immunodeficiency syndrome, or inborn error of metabolism), the vast majority of families who store with private banks pay to have access to stem cells in the future for use in treating degenerative diseases or problems related to injuries or aging. Currently there is no evidence that this use will be feasible or efficacious in such circumstances. Many private banks aggressively advertise their services, promising, for example, "peace of mind and a powerful medical resource used to treat many severe illnesses for your child and loved ones" (47). References to rare and yet-to-be-tested applications for cord blood transplantation play on the fears of new parents wanting to provide every possible advantage for their newborn child (48). In addition to concerns about exploitation, marketing may be inaccurate or misleading: one common reason offered by these private banks for storing autologous cord blood is to have a source of stem cells for transplantation if the child were to develop leukemia. However, most children with leukemias can be cured with conventional chemotherapy alone, and in those for whom this approach fails, allogeneic transplantation is the treatment of choice. Furthermore, leukemic cells have been found in autologous cord blood of children presenting with leukemia from 1-11 years of age (49).

With increasing use of cord blood transplantation, public banks face other challenges. Procuring and providing units for public use in unrelated allogeneic transplantation has involved funding the creation of their inventory from third-party sources. Currently there are approximately 14 public cord blood banks in the United States and approximately 30 more worldwide. All of these banks struggle financially because the revenues gained from the sale of cord blood units for transplantation are not sufficient to support basic operations of a bank that is in the process of building inventory. There is also no requirement for public cord blood banks to list their inventories on a single registry available to all transplant centers. Thus, transplant center staff must be knowledgeable about and search multiple banks and registries to find the best donor for their patients.

In 2004 , after appropriation of $\$ 20,000,000$ by the US Congress to increase the inventory of cord blood units in US public banks, the Health Resources and Services Administration (HRSA) asked the Institute of Medicine (IOM) to perform a study to determine the best way to organize public cord blood banking and distribution to patients undergoing unrelated transplantation, the results of which were published in April 2005 (39, 50). In short, the IOM recommended that HRSA contract with eligible banks to procure approximately 150,000 new, ethnically diverse, unrelated donor cord blood units over the next 5 years. The units will need to meet quality standards as defined by an advisory board, the FDA, and other accrediting agencies. They will also have to be listed on a computerized, web-based, system created to allow searching of all unrelated cord blood and blood obtained from adult donors from a single-point of access. Since the publication of the IOM study, new legislation has been passed by the US House of Representatives (51) and is pending in the Senate (bill number S. 1317) to appropriate funds to establish a National Cord Blood Program, funded and administered through HRSA, and to build a high-qual- 
ity, ethnically diverse inventory of 150,000 new cord blood units to be listed on a combined registry for adult and cord blood donors. Under this new program, patient advocacy must be provided and transplant outcomes collected and evaluated. This funding should enable selected banks to increase operations to build inventory, thereby increasing the number and quality of cord blood units available for unrelated transplantation.

\section{Cord blood use}

Currently, cord blood is used as a source of unrelated hematopoietic stem and progenitor cells for allogeneic transplantation used in the treatment of patients with leukemia, lymphoma, hemoglobinopathies, bone marrow failure syndromes, congenital immunodeficiency syndromes, and inborn errors of metabolism. The fact that cord blood can be transplanted without an identical HLA match increases access to transplantation therapy for patients unable to find a perfectly matched adult donor.

Directed donor cord blood banking is indicated in the small population of women delivering healthy babies where the parents know they carry mutations associated with genetic diseases of the blood or immune system or inborn errors of metabolism or where there is an older affected sibling with one of these diseases who would be a candidate for transplantation therapy. This would include families with children diagnosed with a pediatric malignancy, congenital immunodeficiency syndrome, hemoglobinopathy, or lysosomal storage disease. In these cases, a fully matched or haploidentical sibling cord blood sample of sufficient size could serve as the source for allogeneic transplantation of the known or future affected children in that family.

If, in the future, gene therapy is shown to be safe and effective, autologous cells from an affected child may also be of use. Unfortunately, the initial experience utilizing gene therapy for the treatment of X-linked SCID (resulting from $\gamma$ chain gene mutations), although successful in obtaining gene transfection, expression, and clinical correction of the immune defect, resulted in the unanticipated, aberrant insertion of the vector near an LMO2 oncogene, inducing $\mathrm{T}$ cell acute lymphoblastic leukemia in 4 of 11 patients (52).

Some families carrying mutations for lethal genetic diseases elect to perform preimplantation diagnosis and embryo selection to conceive a healthy child and/or a healthy and HLA-matched donor for their affected child (53). While most of these cases are successful, a few have resulted in misdiagnosis and birth of a baby who is either affected or not a match. Families undergoing this procedure are counseled extensively so that they are aware of the potential risks of the procedure. Some elect to have chorionic villus sampling or amniocentesis to confirm the disease state and HLA typing of the fetus during pregnancy to allow for elective termination if the baby is affected with the genetic disease. Others, for whom termination is not an option, carry the pregnancy to term and obtain confirmatory testing at birth.

In addition to the potential for misdiagnosis, the use of preimplantation genetic diagnosis (PGD) to facilitate creation of a healthy child who could also become an HLA-compatible source of hematopoietic stem cells has raised a number of concerns (54, 55). New reproductive technologies are often met with religious and philosophical objections associated with respect for the sanctity of human life and objections to the discard of human embryos, particularly healthy embryos that are not HLA compatible. Others have questioned parental motivations - whether having a child to save its sibling is the right reason to create a human being. But it has been argued that parents that create a child for such purposes stand on higher moral ground than a host of other parents, who may procreate to carry on their family legacy, "balance" gender in their family, or provide siblings with playmates. Nevertheless, some have argued that PGD to create a stem cell donor be treated as research, in order to ensure institutional oversight, collection of data about adverse effects, and federal standards for minimizing risks to children (56).

Finally, umbilical cord blood cells may have potential applications in the field of regenerative medicine. Cord blood has been shown in some studies to transdifferentiate to a limited extent into nonhematopoietic cells, including those of the brain, heart, liver, pancreas, bone, and cartilage, in experimental culture and animal systems $(57,58)$. Recently it has been demonstrated that both cardiac and glial cell differentiation of cord blood donor cells occurred in recipients of unrelated donor cord blood transplantation as part of a treatment regime for Krabbe disease and Sanfilippo syndrome $(59,60)$. These observations raise the possibility that cord blood may serve as a source of cells to facilitate tissue repair and regeneration in the distant future. While this is purely speculative at this time, developments over the next decade are expected to clarify the potential role of both allogeneic and autologous cord blood in this emerging field.

\section{Concluding comments}

Technology and ethics surrounding the collection, banking, and use of umbilical cord blood has been marked by significant progress over the last 15 years. However, despite rapid progress in many areas, the current US inventory is poorly organized, fragmented, and of varying quality. Recent federal legislation should provide the impetus and resources for the cord blood banking community to organize and adopt uniform high-quality standards, to list on a common national registry, and also to list adult unrelated donors (e.g., similar to the approach currently practiced by the NMDP) while increasing the pool of cord blood donors available for unrelated transplantation.

\section{Acknowledgments}

There are many individuals responsible for the development of cord blood banking and transplantation. These include, but are not limited to, Eliane Gluckman, who performed the first related cord blood transplant in 1988; Gordon Douglas of New York Hospital, who lived in Salisbury, North Carolina, for 1 month, in order to collect the cord blood from the sibling of this child; Ted Boyce, Hal Broxmeyer, and Judy Bard, who hypothesized that cord blood was enriched for hematopoietic stem and progenitor cells; Nancy Kernan and John Wagner, who formed the first voluntary cord blood transplant registry to report outcomes of related cord blood transplants; Pablo Rubinstein, who established the first public cord blood bank in the world; the National Heart, Lung, and Blood Institute, which has supported research in cord blood banking and transplantation; and the National Marrow Donor Program, which has supported public cord blood banks and listed cord blood donors in the unrelated donor registry; the physicians, nurses, and allied healthcare professionals caring for these patients; and the patients and their families, whose courage, dignity, and determination motivate us all.

Address correspondence to: Joanne Kurtzberg, Box 3350, Duke University Medical Center, Durham, North Carolina 27710, USA. Phone: (919) 668-1100; Fax: (919) 681-8942; E-mail: kurtz001@mc.duke.edu. 
1. Gluckman, E., et al. 1989. Hematopoietic reconstitution in a patient with Fanconi's anemia by means of umbilical-cord blood from an HLA-identical sibling. N. Engl. J. Med. 321:1174-1178.

2. Wagner, J.E., Kernan, N.A., Steinbuch, M., Broxmeyer, H.E., and Gluckman, E. 1995. Allogeneic sibling umbilical-cord-blood transplantation in children with malignant and non-malignant disease. Lancet. 346:214-219.

3. Kernan, N.A., et al. 1993. Analysis of 462 transplantations from unrelated donors facilitated by the National Marrow Donor Program. N. Engl. J. Med. 328:593-602.

4. To, L.B., et al. 1992. Comparison of haematological recovery times and supportive care requirements of autologous recovery phase peripheral blood stem cell transplants, autologous bone marrow transplants, and allogeneic bone marrow transplants. Bone Marrow Transplant. 9:277-284.

5. Drobyski, W.R., et al. 1994. Effect of T-cell depletion as graft-versus-host disease prophylaxis on engraftment, relapse, and disease-free survival in unrelated marrow transplantation for chronic myelogenous leukemia. Blood. 83:1980-1987.

6. Rubinstein, P., Rosenfield, R.E., Adamson, J.W., and Stevens, C.E. 1993. Stored placental blood for unrelated bone marrow reconstitution. Blood. 81:1679-1690.

7. Kurtzberg, J., et al. 1996. Placental blood as a source of hematopoietic stem cells for transplantation into unrelated recipients. N. Engl. J. Med. 335:157-166.

8. Wagner, J., Kernan, N., Broxmeyer, H., and Gluckman, E. 1996. Successful transplantation of HLAmatched and HLA-mismatched umbilical cord blood from unrelated donors: analysis of engraftment and acute graft-versus-host disease. Blood. 88:795-802.

9. Gluckman, E., et al. 1997. Outcome of cord-blood transplantation from related and unrelated donors. N. Engl. J. Med. 337:373-381.

10. Rubinstein, P., et al. 1998. Outcomes among 562 recipients of placental-blood transplants from unrelated donors. N. Engl. J. Med. 339:1565-1577.

11. Rocha, V., et al. 2000. Graft-versus-host disease in children who have received a cord-blood or bone marrow transplant from an HLA-identical sibling. N. Engl. J. Med. 342:1846-1854.

12. Barker, J.N., et al. 2001. Survival after transplantation of unrelated donor umbilical cord blood is comparable to that of human leukocyte antigenmatched unrelated donor bone marrow: results of a matched-pair analysis. Blood. 97:2957-2961.

13. Rocha, V., et al. 2001. Comparison of outcomes of unrelated bone marrow and umbilical cord blood transplants in children with acute leukemia. Blood. 97:2962-2971.

14. Locatelli, F., et al. 2003. Related umbilical cord blood transplantation in patients with thalassemia and sickle cell disease. Blood. 101:2137-2143.

15. Hall, J.G., Martin, P.L., Wood, S., and Kurtzberg, J. 2004. Unrelated umbilical cord blood transplantation for an infant with B-thalassemia major. J. Pediatr. Hematol. Oncol. 26:382-385.

16. Staba, S., et al. 2004. Cord-blood transplants from unrelated donor in patients with Hurler's syndrome. N. Engl. J. Med. 350:1960-1969.

17. Myers, L.A., Hershfield, M.S., Neale, W.T., Escolar, M., and Kurtzberg, J. 2005. Purine nucleoside phosphorylase deficiency (PNP-Def) presenting with lymphopenia and developmental delay: successful correction with umbilical cord blood transplantation. J. Pediatr. 145:710-712.

18. Escolar, M.L., et al. 2005. Transplantation of umbilical-cord blood in babies with infantile Krabbe's disease. N. Engl. J. Med. 352:2069-2081.
19. Laughlin, M.J., et al. 2001. Hematopoietic engraftment and survival in adult recipients of umbilicalcord blood from unrelated donors. N. Engl. J. Med. 344:1815-1822.

20. Long, G.D., et al. 2003. Unrelated umbilical cord blood transplantation in adult patients. Biol. Blood Marrow Transplant. 9:772-780.

21. Laughlin, M.J., et al. 2004. Outcomes after transplantation of cord blood or bone marrow from unrelated donors in adults with leukemia. N. Engl. J. Med. 351:2265-2275.

22. Rocha, V., et al. 2004. Transplants of umbilical-cord blood or bone marrow from unrelated donors in adults with acute leukemia. N. Engl. J. Med. 351:2276-2285.

23. Takahashi, S., et al. 2004. Single-institute comparative analysis of unrelated bone marrow transplantation and cord blood transplantation for adult patients with hematologic malignancies. Blood. 104:3813-3820.

24. Fruchtman, S.M., et al. 2004. The successful treatment of severe aplastic anemia with autologous cord blood transplantation. Biol. Blood Marrow Transplant. 10:741-742.

25. Gluckman, E., et al. 2004. Factors associated with outcomes of unrelated cord blood transplant: guidelines for donor choice. Exp. Hematol. 32:397-407.

26. Jaroscak, J., et al. 2003. Augmentation of umbilical cord blood (UCB) transplantation with ex vivoexpanded UCB cells: results of a phase 1 trial using the AastromReplicell system. Blood. 101:5061-5067.

27. McNiece, I., Harrington, J., Turney, J., Kellner, J., and Shpall, E.J. 2004. Ex vivo expansion of cord blood mononuclear cells on mesencymal stem cells. Cytotherapy. 6:311-317.

28. Barker, J.N., et al. 2005. Transplantation of 2 partially HLA-matched umbilical cord blood units to enhance engraftment in adults with hematologic malignancy. Blood. 105:1343-1347.

29. Barker, J.N., et al. 2003. Rapid and complete donor chimerism in adult recipients of unrelated donor umbilical cord blood transplantation after reducedintensity conditioning. Blood. 102:1915-1919.

30. Chao, N.J., et al. 2004. Adult recipients of umbilical cord blood transplants after nonmyeloablative preparative regimens. Biol. Blood Marrow Transplant. 10:569-575.

31. Fernandez, M.N., et al. 2001. Cord blood transplants: early recovery of neutrophils from co-transplanted sibling haploidenitcal progenitor cells and lack of engraftment of cultured cord blood cells, as ascertained by analysis of DNA polymorphisms. Bone Marrow Transplant. 28:355-364.

32. Fraser, J.K., et al. 1998. Cord blood transplantation study (COBLT): cord blood bank standard operating procedures. J. Hematother. 7:521-561.

33. The Cord Blood Transplantation Study. The EMMES Corp. http://www.emmes.com.

34. Kurtzberg, J., et al. 2005. Results of the cord blood transplantation (COBLT) study unrelated donor banking program. Transfusion. 45:842-855.

35. Cairo, M.S., et al. 2005. Characterization of banked umbilical cord blood hematopoietic progenitor cells and lymphocyte subsets and correlation with ethnicity, birth weight, sex, and type of delivery: a cord blood transplantation (COBLT) study report. Transfusion. 45:856-866.

36. Sugarman, J., Kurtzberg, J., Box, T.L., and Horner, R.D. 2002. Optimization of informed consent for umbilical cord blood banking. Am. J. Obstet. Gynecol. 187:1642-1646.

37. Vawter, E.R., et al. 2002. A phased consent policy for cord blood donation. Transfusion. 42:1268-1274.

38. Jenkins, G.L., and Sugarman, J. 2004. The importance of cultural considerations in the promotion of ethical research with human biological material [review]. J. Lab. Clin. Med. 145:118-124.

39. Burgio, B.R., Gluckman, E., and Locatelli, F. 2003. Ethical reappraisal of 15 years of cord blood transplantation. Lancet. 361:250-252.

40. Steinbrook, R. 2004. The cord-blood-bank controversies [comment]. N. Engl. J. Med. 351:2255-2257.

41. Anonymous. 2004. Pharmastem Therapeutics, Inc. v. ViaCell, Inc. WL 2127192. C.A. No. 02-148 GMS (D. Del.).

42. Anonymous. 2005. US Patent Office rejects PharmaStem cord blood stem cell patents. Today's stem cell research: stem cell research medical and health news. http:/ www.stemnews.com/archives/000430.html.

43. Chapman, A.R., Frankel, M.S., and Garfinkel, M.S. 1999. Stem cell research and applications: monitoring the frontiers of biomedical research. American Association for the Advancement of Science. Washington, DC, USA. http://www.aaas.org/spp/ $\mathrm{sfrl} /$ projects/stem/report.pdf.

44. Fisk, N.M., Roberts, I.A.G., Markwald, R., and Mironov, V. 2005. Can routine commercial cord blood banking be scientifically and ethically justified. PLoS Med. 2:87-90.

45. Ecker, J.L., and Greene, M.F. 2005. The case against private umbilical cord blood banking. Obstet. Gynecol. 105:1282-1284.

46. Sugarman, J., et al. 1997. Ethical issues in umbilical cord blood banking. Working Group on Ethical Issues in Umbilical Cord Blood Banking [review]. JAMA. 278:938-943.

47. Cord Blood Registry. http://www.cordblood.com/ index.asp.

48. Assas, G.I. 1999. Waste and longing - the legal status of placental-blood banking. N. Engl. J. Med. 340:1521-1524.

49. Rowley, J. 1998. Backtracking leukemia to birth. Nat. Med. 4:150-151.

50. Committee on Establishing a National Cord Blood Stem Cell Bank Program. 2005. Cord blood: establishing a national hematopoietic stem cell bank program. National Academies Press. Washington, DC, USA. 320 pp.

51. Anonymous. 2005. Stem Cell Research Enhancement Act of 2005. HR 810. 109th Congress, 1st sess. Congr. Rec. (Dly. Ed.). 151:H3795-H3809.

52. Hacein-Bey-Abina, S., et al. 2003. A serious adverse event after successful gene therapy for X-linked severe combined immunodeficiency. N. Engl. J. Med. 348:255-256.

53. Verlinsky, Y., et al. 2004. Preimplantation HLA testing. JAMA. 291:2079-2085.

54. Fost, N.C. 2004. Conception for donation. JAMA. 291:2125-2126.

55. Burgio, G.R., and Locatelli, F. 2000. Ethics of creating programmed stem-cell donors. Lancet. 356:1868-1869.

56. Wolf, S.M., Kahn, J.P., and Wagner, J.E. 2003. Using preimplantation genetic diagnosis to create a stem cell donor: issues, guidelines and limits. J. Law Med. Ethics. 31:327-339.

57. Porada, G.A., Porada, C., and Zanjani, E.D. 2004. The fetal sheep: a unique model system for assessing the full differentiative potential of human stem cells. Yonsei Med. J. 45(Suppl.):7-14.

58. Kogler, G., et al. 2004. A new human somatic stem cell from placental cord blood with intrinsic pluripotent differentiation potential. J. Exp. Med. 200:123-135.

59. Hall, J., Crapnell, K.B., Staba, S., and Kurtzberg, J. 2004. Isolation of oligodendrocyte precursors from umbilical cord blood [abstract]. Biol. Blood Marrow Transplant. 10:67.

60. Crapnell, K.B., Turner, K., Hall, J.G., Staba, S.L., and Kurtzberg, J. 2003. Umbilical cord blood cells engraft and differentiate in cardiac tissues after human transplantation [abstract]. Blood. 102:153b. 